\title{
CORPO E IDENTIDADE: QUESTÕES DE PSICOPATOLOGIA INDIVIDUAL E COLETIVA
}

Stéphane Thibierge

\author{
Stéphane Thibierge \\ Psicanalista em \\ Paris, mestre de \\ conferências na \\ Universidade \\ Paris VII, membro \\ da Associação \\ Lacaniana \\ Internacional.
}

Tradução

Fabiana Campos Baptista Doutora em Psicopatologia e Psicanálise pela Université Paris Diderot Sorbonne Cité.

Natália Vidal Doutoranda do Programa de Pós-Graduação em Teoria Psicanalítica (PPGTP) da UFRJ.
RESUMO: Interroga-se a relação com o corpo e a questão da identidade no sujeito contemporâneo, levando-se em conta, sobretudo, os múltiplos operadores virtuais que o identificam hoje e o fluxo incessante de mensagens e informações do qual ele é o destinatário. Destaca-se, em especial, a angústia resultante desse processo para o sujeito moderno. Evoca-se, também, como são suscitados nesse contexto os principais ideais da identidade e suas incidências subjetivas. Na conclusão, menciona-se como a psicanálise pode abordar, a partir daí, a questão da alteridade.

Palavras-chave: Corpo, identificação, objeto, informação, psicologia coletiva.

ABSTRACT: Body and identity: individual and collective psychopathology issues. This paper deals with the relationship to the body and the issue of identity in the contemporary subject. The multiple virtual operators that identify this subject nowadays and the continuous flow of messages and information forwarded to this same subject are considered here. The anguish resulting from this process to the modern subject is emphasized. How the main ideals of identity and its subjective effects are raised in this context is also discussed. As a conclusion, the question of how psychoanalysis can approach the issue of otherness from this point is mentioned. Keywords: Body, identity, object, information, collective psychology.

DOI - http://dx.doi.org/10.1590/S1516-14982015000200004 


\section{INTRODUÇÃO}

Deparamo-nos hoje, de forma inédita por sua urgência e insistência, com a questão da identidade, quer se trate da identidade subjetiva individual ou da coletiva, quando se busca reconhecer grupos ou comunidades. Neste artigo, nos propomos a explicitar essa questão sob seus dois aspectos, individual e coletivo, visando esclarecê-la, em especial, a partir de certas modalidades contemporâneas da relação com o corpo. Do ponto de vista da psicologia coletiva, as questões e as problemáticas identitárias nunca foram tão atuais, como podemos constatar com facilidade. De fato, é notável que, hoje, a questão da identidade toque mais ou menos de perto todos os grupos sociais que possuem, de uma maneira ou de outra, uma forma instituída: desde a família dita "nuclear” à nação ou grupos de nações, passando por todas as formas reconhecíveis do coletivo. O laço social como tal, qualquer que seja ele e qualquer que seja a amplitude da comunidade a que se refere, parece ter que ser consolidado como se estivesse, em si mesmo, ameaçado ou precário. Essa consolidação encontra com frequência sua expressão mais eficaz no reconhecimento mútuo e na afirmação comum de um ou mais traços identitários.

Freud (1923/1984) forneceu, desde 1923, uma análise ainda hoje bastante atual dos mecanismos dessa psicologia coletiva. A identidade assim reivindicada é afirmada de modo tão mais forte quanto maior seu caráter imaginário — isto é, conforme seja reconhecida e endossada por todos e por cada um com maior facilidade. Mas por esse motivo, como se sabe, ela vem necessariamente se opor a outras identidades coletivas que reivindicam traços distintos de reconhecimento. Tais oposições são, portanto, mais violentas e exclusivas conforme os traços identitários a que se referem revelem a preponderância do imaginário — ou seja, de uma separação unívoca entre dentro e fora, o mesmo e o outro, eu e não eu. Sabemos como se verifica nos dias de hoje, em nome da identidade coletiva, a incidência dessas oposições.

Do ponto de vista da psicologia individual, pode-se ainda acentuar sem dificuldades o valor atribuído hoje à noção de identidade, e a importância que damos ao fato e à consciência de termos uma identidade — uma problemática que pode, aliás, colocar em evidência essa noção. Há neste ponto uma inquietude e um tormento específicos da Modernidade, sobre os quais gostaríamos de nos deter aqui. Em todo caso, um elemento parece se verificar do ponto de vista psicopatológico: o sujeito moderno está pronto a sacrificar muito, e às vezes até sua vida, a essa exigência de identidade, desde que o sacrifício lhe garanta uma.

Eis, portanto, uma questão individual e coletiva pertinente, à qual gostaríamos de tentar lançar luz, sobretudo a partir da relação contemporânea com o corpo e, em particular, da maneira pela qual o corpo do sujeito moderno pode ser atingido e afetado por efeitos até então inéditos por sua natureza e amplitude. 


\section{PONTO DE PARTIDA CLÍNICO}

Do ponto de vista clínico, uma das particularidades da experiência das psicoses reside no modo exemplar com que esta estrutura nos confronta à dificuldade experimentada no processo de identificação. Dificuldade esta que é experimentada, em diferentes graus, pelo sujeito psicótico ${ }^{1}$ no despedaçamento que ele vivencia de seu próprio corpo e de sua projeção especular. Certas psicoses nos ensinam também de que forma um delírio pode vir tentar responder a essa dificuldade, situando a identidade do lado de um Um perseguidor, a quem o sujeito psicótico atribui os motivos de sua queixa. No entanto, ao ser localizada nesse mesmo Um, a queixa assim sustentada se reveste de uma consistência que, com frequência, assume um valor identitário. Podemos ilustrar essa questão a partir das observações clássicas que devemos a Clérambault.

Clérambault mostrou muito bem como toda uma vertente das psicoses, as psicoses a que ele denominava "passionais", era identificável a partir de três categorias principais, que ele isolou e descreveu. Elas representam três tentativas da parte do sujeito de dar à identidade uma forma una e completa, projetada como ideal, mas de um modo sempre invertido e, ao mesmo tempo, persecutório: é o outro que detém minha identidade, e me deixa inconsistente diante de sua unidade ideal. Essas três modalidades passionais da questão da identidade para um sujeito foram assim isoladas por Clérambault:

- o delírio de ciúme: o outro arrebata meu ser, ele representa o ideal do meu eu e ao mesmo tempo me despossui;

- o delírio de reivindicação: o outro me lesa e tira de mim o que me faz ser eu mesmo;

- o delírio de erotomania: o outro me ama, ele me escolheu de forma absoluta como objeto de amor, objeto do seu amor.

Estas três psicoses "passionais" são afecções que permitem perceber de uma forma muito direta como se constitui a identidade ${ }^{2}$. E, se as evocamos aqui é porque elas nos ensinam sobre nossos próprios tormentos, portanto, sobre questões que não são exclusivas dos sujeitos psicóticos. Quem dentre nós não conheceu, por exemplo, o que chamamos de ciúme? Será que a reivindicação não é uma experiência bastante comum em nossa existência? É, enfim, fácil perceber como cada um de nós é persuadido sem dificuldades de que o outro nos ama, ou, ainda, de que somos “amáveis”. Em nossa forma habitual de pensar,

\footnotetext{
${ }^{1}$ Esse termo, "sujeito psicótico", pode trazer algumas dificuldades, uma vez que não há sempre sujeito na psicose. Contudo, o manteremos por considerar importante, quando nos endereçamos ao psicótico, o ouvimos, o lemos, supor um sujeito enquanto essa suposição é possível. Ainda que ela não o seja sempre.

2 Pois nelas, os diversos elementos que formam a identidade, aparecem decompostos em sua estrutura.
} 
consideramos com mais facilidade que a desordem do mundo advém do vizinho do que de nós mesmos.

A questão da identidade nem sempre foi tão presente. Podemos notar, por exemplo, como os povos da Antiguidade, cujos textos conservamos, não nos deixam muitos traços da existência de um tormento semelhante em seus escritos. Assim, se nesta época, gregos, judeus, romanos, só para citar alguns, já eram capazes de evocar e articular a referida questão, eles o faziam de um modo muito distinto do que ocorre na atualidade - ou seja, sem a inquietação e a paixão que ela suscita entre nós. Tampouco faziam dela uma questão central ou alguma espécie de princípio.

Podemos avançar aqui diversas razões que podem contribuir para dar conta, hoje, da importância dada à identidade. Elas se referem, sobretudo:

- à incidência contemporânea da ciência moderna e à maneira pela qual ela situa a questão do corpo;

- às múltiplas modalidades contemporâneas da imagem, e suas consequências subjetivas;

- enfim, à informação e à maneira como esta é recebida pelo sujeito hoje.

\section{A CIÊNCIA MODERNA, O CORPO E A ANGÚSTIA}

Relacionamos com frequência o nascimento da ciência moderna, entre outros aspectos, ao momento cartesiano, isto é, ao isolamento realizado por Descartes de uma certeza primeira e fundadora. Como sabemos, a certeza cartesiana reenvia à enunciação fundadora de um sujeito capaz de se apreender enquanto desconectado do próprio corpo e de suas contingências, para se assumir apenas a partir da autonomia suposta de seu pensamento. Se a certeza cartesiana pode ser considerada como o início da ciência moderna, é na medida em que ela funda um domínio autônomo em relação às contingências do corpo do sujeito. Este domínio é por excelência o de uma escrita científica, isto é, o de uma escrita que não concerne, em particular, ao sentido ou à interpretação, nem à castração, nem, enfim, a coisa alguma relativa a este corpo. É isso o que faz o poder e a riqueza das produções da ciência moderna, mas é também o meio pelo qual sua autonomia pode se abster de toda relação de pura contingência com nosso corpo. De fato, o corpo concreto é aqui colocado deliberada e metodicamente de lado.

Encontramos nesse afeto que é a angústia (ver p. ex. Freud 1925/2011, Lacan 1962-63/2004) um modo flagrante de retorno do que, concernente ao corpo, é excluído de maneira radical pela ciência moderna. Esta via aberta pela ciência, e que dá ao corpo e às suas contingências um lugar determinado, retorna como 
questão ao sujeito sob a forma de angústia: corpo desde então disponível para que, para qual desejo ou para atender a qual demanda opaca? ${ }^{3}$

A angústia é, sem dúvida, o afeto mais sensível e mais radical em sua dimensão própria de afeto. Ela interessa, é claro, ao corpo, já que vem lembrar a presença e o real de uma maneira pregnante em especial na tradição ocidental, que se mostra muito específica na sua relação com o corpo, o que leva a pensar que não foi por acaso que ali pôde se produzir o momento cartesiano. Outras tradições, como a chinesa, por exemplo, não estão organizadas da mesma maneira: pode-se dizer que elas dão ao corpo um lugar muito mais importante e marcado como tal. Esse é o motivo pelo qual conferem de bom grado destaque às práticas do corpo, ou a um saber do corpo encarados com desconfiança pela tradição ocidental, quando não são desqualificados por esta última. É sobretudo por ter sido levada a colocar essa relação, específica, ao corpo — relação de exclusão ou de abstração — que Descartes representa o momento plenamente explicitado e fundador na tradição filosófica e científica. Ora, a angústia vem nos lembrar, e talvez de modo ainda mais flagrante na tradição ocidental, que o corpo nos provoca um embaraço real pelo qual somos importunados.

Do ponto de vista clínico, esse embaraço no que se refere à nossa relação com o corpo é, aliás, notável: não sabemos muito bem o que fazer com ele. É isso o que tende a conferir ao corpo, hoje, em geral um estatuto de "objeto disponível"4 não para o nosso uso "privado”, mas, de modo ainda mais radical, pelo Outro. Este corpo é cedível: ele deve ser cedido ao Outro e não nos pertence de maneira alguma, ao contrário do que sugere um ideal imaginário. Mas a dificuldade é que não sabemos a quais fins ele deve ser cedido. Há, em relação a isso, uma certa opacidade. É por isso que não sabemos o que fazer com ele. E é esta questão do uso, assim como a do lugar do nosso corpo, que nos retorna sob a forma de angústia.

Parece que é esta angústia que leva o sujeito moderno a procurar na identidade uma estabilização ou uma consolidação imaginárias. ${ }^{5}$

\footnotetext{
${ }^{3}$ Voltaremos a esta questão mais à frente em nossa discussão quando nos referirmos ao estatuto que é conferido, hoje, ao corpo.

${ }^{4} \mathrm{O}$ corpo, hoje, pode assumir para o sujeito um estatuto análogo ao ao dos objetos disponíveis na lógica de mercado. Atualmente é possível, por exemplo, pagar intervenções capazes de modificar esse corpo, "moldá-lo" segundo as escolhas do sujeito/consumidor.

${ }^{5}$ Essa angústia pode, ela mesma, ser considerada como um afeto especificamente moderno. Kierkegaard (1844/1990) sublinhou a importância da angústia como elemento principal e determinante da existência do sujeito. Motivo pelo qual ele evocava esse termo difícil, conceito de angústia, termo paradoxal posto que em termos clássicos, um afeto e um conceito não são do mesmo registro, em especial quando se trata do afeto que mais se furta à explicação conceitual: a angústia. Freud (1925/2011) situa, também ele, a função desta na neurose moderna, e Lacan (1963-63/2004) consagrou à angústia um seminário inteiro em 1962-1963 - para não citar senão esses três autores. Lacan situa o domínio da angústia ali onde o sujeito recebe o desejo do Outro como pura questão.
} 


\section{IMAGENS CONTEMPORÂNEAS}

Por outro lado, levando-se em conta a maneira como somos atravessados, hoje, pelas dificuldades relativas à identidade, não podemos negligenciar o fato de que vivemos de uma forma que permite a cada um - pelos meios técnicos mais variados e cada vez mais sofisticados - poder pensar que é identificável. Isso se evidencia muito importante para o que nos interessa aqui, na medida em que dispomos, assim, de suportes tecnológicos concretos e sofisticados para sugerir a noção de uma identidade e nos fornecer traços imaginários.

Estes suportes, que são reais, nos permitem, por exemplo, nos “unir”, isto é, nos constituir como referentes designáveis na realidade. O fato de sermos, desta forma, atingíveis sem grandes dificuldades nos sugere que temos uma consistência e um correlato apontável e mostrável de realidade. Do mesmo modo, podemos de maneira constante ser colocados em imagens pelos outros - é fácil produzir imagens nossas. E, de maneira geral, o que chamamos de "virtual", e que reenvia hoje a modos operatórios bastante variáveis e de grande amplitude, coloca à disposição meios consideráveis que nos permitem ser identificados na realidade. Isso favorece, é claro, a sugestão de uma identidade, uma vez que somos identificáveis e identificados. Mas o corolário desta crença é estarmos ainda mais expostos à angústia que evocamos.

Com efeito, quando somos "identificados" - por uma imagem, uma foto, um registro ou uma outra aparelhagem ou dispositivo tão comuns hoje - ou mesmo apenas pelo fato de podermos estar presentes de formas diferentes e que nem sempre conhecemos, podemos ser tomados, com facilidade, pela angústia. E esse é de fato um sintoma que, sem dúvida, parece ser mais frequente hoje do que antes.

O que pode nos angustiar assim?

Logo que somos identificados desta forma múltipla e repetida, não podemos nos esquivar de colocar a questão: por quem somos identificados? Ou: para quê? E em nome de que somos identificados? Dito de outra maneira, isso nos confronta com a questão de saber o que fazer em relação a essas diversas identificações do nosso corpo, da nossa imagem, do nosso nome. O que esperam de mim? Por que sou assim apontado, notado, designado a partir dessas modalidades diversas e, com frequência, discordantes?

\section{INFORMAÇÃO E MENSAGENS}

Às referidas modalidades da imagem e à maneira como elas nos afetam, podemos acrescentar aqui os efeitos sobre o sujeito contemporâneo de tudo o que a ele se direciona a título de informação, ou seja, as mensagens que ele recebe em grande 
número e de forma quase contínua em estado de vigília. Podemos ilustrar esse ponto de forma simples a partir do que chamamos de "informações", da forma como são difundidas pelos diferentes meios de comunicação que as fornecem.

Essas informações foram durante muito tempo apresentadas sob um quadro e uma articulação que favoreciam a forma da narrativa. A dimensão do sentido era levada em consideração o suficiente para que o destinatário da mensagem pudesse fazer alguma coisa com ela: recebê-la e elaborar uma resposta passível de ser compartilhada em graus variados em outras mensagens (conversas, palavras faladas ou escritas endereçadas a possíveis interlocutores em diferentes contextos). Os jornais escritos constituíram, por longo período, um suporte privilegiado desse tipo de troca.

Essas modalidades de informações e mensagens mudaram muito. Podemos perceber que elas pouco a pouco deixaram de lado o registro da narrativa para assumir novas formas, ao mesmo tempo mais diretas e menos articuladas.

Nas sociedades modernas, recebemos em geral de forma contínua (a que chamamos streaming) mensagens em quantidades cada vez maiores e que apresentam em geral as seguintes características:

1) São produzidas e enviadas sem um laço discursivo reconhecível, às vezes sem nenhum apelo à interpretação, como puros "choques" visuais, auditivos, ou outros. Em outras palavras, elas se apresentam como uma "parataxe" — justapostas umas ao lado das outras, e não articuladas em uma sintaxe. O telejornal fornece um exemplo desse fluxo de mensagens, assim como os canais de informação em cadeia, as informações enviadas e substituídas a todo instante, em graus variáveis, nas redes sociais, ou ainda, as mensagens com as quais nos deparamos em suportes bastante numerosos e diversificados quando nos deslocamos no espaço urbano ou social.

2) Ainda que sejamos os destinatários dessas mensagens, não podemos respondê-las, pelo simples fato de serem por demais numerosas. São, aliás, tão numerosas que a condição para sua recepção, em determinado momento, é o apagamento daquilo que as precede, motivo pelo qual a memória seria saturada por sua quantidade. Esfacelamento, também, da memória na medida em que ela caminha de mãos dadas com a recepção de informação.

Como podemos precisar a situação do sujeito contemporâneo destinatário dessas mensagens? Sem dúvida, aqui se faz necessário lembrar uma das condições principais da troca, do intercâmbio humano, uma vez que ela se produz sempre, de modo direto ou não, no horizonte da fala. Notemos que a fala comporta essa necessidade segundo a qual toda pergunta enseja uma resposta — o silêncio podendo, dependendo da circunstância, constituir uma resposta possível, a ser ouvida, também ela, no horizonte da fala. 
Assim, uma vez que somos os destinatários dessas mensagens, e mesmo se elas não nos são propriamente "endereçadas" — somos seus alvos, mas elas não são marcadas por nenhum endereçamento singular — somos, também, convocados, de forma consciente ou não, a responder. Devemos responder na medida em que uma questão demanda resposta, e é desta forma que recebemos tais mensagens. Entretanto, não podemos fazê-lo: carecemos, para isso, do mínimo de tempo necessário para receber a mensagem, a partir dela produzir uma leitura - porventura uma interpretação — , e, enfim, uma resposta possível. Recebemos mensagens demais, de maneira contínua, para dispor desse tempo.

Mas em decorrência disso, somos afetados pelo que se produz quando deixamos sem resposta uma mensagem recebida, ou quando não temos o tempo necessário para interpretar uma mensagem. Resulta daí, não sem frequência, a angústia — O que se quer de mim? - e a culpabilidade — pois, diante da mensagem recebida, encontro-me incapaz de dar uma resposta, estou impotente para responder. Como sabemos, as técnicas da comunicação publicitária jogam bastante com esses mecanismos, por sinal, eficazes. Angústia e culpabilidade estas que estão presentes em graus variados no que chamamos hoje de estresse. Essa noção, vale lembrar, foi tomada de empréstimo à psicologia experimental, para qualificar o comportamento de animais colocados de modo intencional em situações às quais eles não podiam responder, o tempo todo sendo solicitados de maneira cada vez mais forte.

A referida estrutura da informação, bem como a das imagens, à qual o sujeito moderno está assujeitado, favorece uma demanda de identidade reforçada ou consolidada. De fato, ela contribui para tornar precária a posição subjetiva de cada um e a maneira como se pode assumir a responsabilidade por esta posição. Que o sujeito possa ser visado ou fixado a todo instante por uma imagem que o alfineta, cria circunstâncias que não facilitam as condições de uma responsabilidade passível de ser assumida — ou seja, no campo da fala — ou que podem mesmo invalidá-la de forma pura e simples. Decorre daí essa consequência pouco evitável de uma demanda mais imperiosa de identidade, e de uma identidade tão mais consolidada quanto mais um sujeito se encontre de forma precária, e desorientado, no exercício da responsabilidade nesse campo.

Tais considerações nos conduzem a lembrar as condições do advento, para cada um, da relação ao que chamamos identidade.

\section{O RECONHECIMENTO E O ESPELHO}

Para esclarecer a questão que nos colocamos no que se refere à nossa relação com a identidade, lembramos que o animal humano, isto é, o animal afetado pela linguagem, apresenta a especificidade, sublinhada por Lacan, de uma pre- 
maturação do nascimento. Dito de outra forma, o homem nasce prematuro em relação às necessidades de sua vida. Seu nascimento o joga em uma situação de desamparo e de dependência radical em relação ao outro, em geral, à mãe. Esta dependência radical se traduz pelo fato de que nós todos fomos objetos do outro, queiramos ou não: objeto do que esperam de nós, da demanda ou do desejo de um Outro, para além de outrem ou de um semelhante. Começamos sempre deste momento e dessa cessão que nos faz em primeiro lugar objeto deste Outro.

Esse momento pelo qual passa a princípio o sujeito humano, momento em que reconhecemos nossa própria imagem, não é simples nem evidente, já que para os sujeitos psicóticos, sobretudo, ele representa uma grande dificuldade e às vezes uma impossibilidade. Como se sabe, esta imagem especular cujo reconhecimento no espelho apenas em aparência ocorre de forma simples, não acontece ou não se mantém na psicose. Ela é despedaçada ou, ao contrário para dar aqui dois extremos — - unificada de forma tão única e condensada que o sujeito é excluído dela. A imagem torna-se, então, de tal modo absoluta na sua presença que o sujeito, enquanto corpo real, é ameaçado por ela. E esta ameaça pode, assim que é levada a um paroxismo de angústia, dar uma percepção do outro como ameaça persecutória ou causar passagens ao ato de autodestruição.

Quando um sujeito não é psicótico, e a fase da imagem especular funcionou, ele está na situação de poder se reconhecer no espelho. Em geral, logo que nos vemos no espelho, nos reconhecemos: “Ah, sou eu!”. Isso nos parece, inclusive, bastante natural e, no entanto, mereceria nos surpreender vermos uma imagem e dizer: "sou eu".

Foi o que Lacan tentou elucidar em seu artigo sobre O estádio do espelho (LACAN, 1966). Este texto mostra entre outras coisas como a referida condição de objeto - que é a da criança em seu nascimento, isto é, a condição do corpo despedaçado pela demanda do Outro - conheceu em determinado momento, na neurose, um corte. Não sem razão, amiúde atribui-se este corte à presença efetiva do pai, a saber, alguém que vai permitir, nos casos favoráveis, que haja uma interrupção da demanda da mãe em relação à criança. O pai pode permitir que haja este corte, o que torna possível o fato de a criança não ficar por completo entregue ao Outro. É isso o que permite que nos reconheçamos nesta forma de unidade que constitui nossa imagem. Este corte é a condição da nossa imagem.

\section{O DESCONHECIMENTO DOS OBJETOS E OS IDEAIS}

Nosso possível reconhecimento no espelho, a maneira como reconhecemos a imagem como sendo a nossa, supõe um esquecimento, por assim dizer, da condição inicial de objeto. No momento em que nos tomamos por nossa imagem, esquecemos de onde viemos, esquecemos que estivemos na condição radical de 
objeto. Esta condição não cessa quando nos identificamos com nossa imagem, mas ela é esquecida ou, de modo mais preciso, ela é recalcada. Podemos mesmo afirmar que a imagem especular, como representação, é correlativa do recalque, posto ser seu efeito direto. É por isso que ela é sempre precária ou fragmentada nas psicoses, pelo fato de que o recalque não teve lugar.

É neste momento, com o estádio do espelho, que começa o ciclo sem fim de tentativas de adequação à imagem e ao ideal que ela representa e à série de desconhecimentos e de engodos que nos atormentam e que nos faz procurar, às vezes de forma desesperada, uma identidade. ${ }^{6}$ Evocaremos aqui, em particular, três ideais, entre os principais:

1) Em primeiro lugar, a ideia e o ideal de um eu. É a ideia de que o “eu” forma uma unidade e uma coerência que me conferem uma personalidade. Dizemos então que temos uma personalidade, sem refletir muito sobre o fato de que isso não é evidente. Nos Estados Unidos e no movimento psicanalítico, o referido ideal da personalidade encontrou uma expressão muito marcante e muito comentada, já que a ele se chamava "eu autônomo” (autonomus ego). O objetivo de uma psicanálise era sobretudo o de se tornar um "eu autônomo". Isso mostra até que ponto podemos logo esquecer o fato de que somos comandados, quer queiramos ou não, por um objeto, e de partida por este objeto que representamos de início para o Outro. Em seguida, a demanda do Outro deixa entrever suas ressonâncias sob a forma do objeto que nós mesmos vamos muitas vezes procurar sem que o saibamos. E só podemos conduzir nossa existência, como sujeito do desejo, se aceitarmos esta alienação de início a um objeto que nos determina. O que vai contra a ideia ou a noção da nossa identidade, independentemente da maneira como a concebemos. Isto quer dizer que a questão da identidade, assim que ela se coloca de forma urgente ou imperativa, o faz via de regra contra o fato de que podemos saber alguma coisa do objeto que nos conduz, isto é, saber alguma coisa do nosso desejo. Não queremos ouvir falar de nosso desejo: o que não surpreenderá em nada um psicanalista, já que só podemos formar um eu ou uma imagem desta forma. É o que Freud chamava de recalque desse desejo.

2) Em seguida vêm a ideia e o ideal do grupo, tão em voga e tão atuais hoje, como lembramos no início do artigo. Os grupos e os pertencimentos coletivos são buscados na medida em que sustentam um sujeito em uma identificação imaginária, ou seja, em uma identidade. Mas, da mesma maneira com podemos nos agarrar ao nosso eu, podemos nos agarrar a nossos grupos de pertencimento ou encontrar novos, se aqueles que conhecemos não se revelam unificados e eficazes o suficiente enquanto grupos. Os sujeitos mais precários e mais incertos

\footnotetext{
${ }^{6}$ Vamos nos reportar, aqui, com grande proveito, ao livro de Alice Massat, Le succès de l'imposture (Massat, 2013) Cf. também, e entre outros, nossa obra Clinique de l'identité (PUF, 2007).
} 
no que diz respeito aos traços e nomes que os representam no simbólico — na linguagem — são também os que mais se encontram na busca de tais identidades coletivas. E estas são tão mais eficazes em suas funções de suporte imaginário quanto mais simples e menos sujeitos à interpretação são os traços identitários a serem reconhecidos, ou seja, mais unívocos. Entra-se, por esta via, na lógica intransigente e segregadora, até mesmo mortal, que evocamos no início a propósito dos problemas identitários contemporâneos.

3) Uma terceira forma, também clássica, pela qual tentamos assegurar para nós mesmos uma identidade, é a ideia de um mundo: uma "concepção de mundo”, como assinalava Freud (1932a/1971). ${ }^{7}$ Através dela, temos a sensação de possuir um norte, uma certa orientação, assim como a sensação de que nossas vidas são dotadas de coerência, de que nelas as coisas encontram sentido desde as realidades a princípio mais simples de nossa experiência sensível, até as questões mais difíceis que podemos encontrar na nossa existência. Escrevia Freud (1932a/1971):

“Creio que uma concepção de mundo é uma construção intelectual, capaz de resolver, a partir de um único princípio, todos os problemas postos pela nossa existência. Ela responde assim a todas as questões possíveis e permite dispor em um lugar determinado tudo o que pode nos interessar. É perfeitamente natural que os homens tentem forjar para si mesmos semelhante representação do mundo e que seja este um de seus ideais. A fé que a ela acrescentam lhes permite sentirem-se mais à vontade na vida, saber em direção a que se encaminham e de que maneira podem, de forma mais útil, empregar seus afetos e seus interesses.” (FREUD, 1932a/1971, p. 208)

Freud via na arte, na filosofia ou na religião, sobretudo nesta última, três formas das mais comuns que pode assumir nossa aspiração a uma concepção de mundo. Contudo, ele considerava a religião, em especial, como passível de crítica, nos casos em que ela busca apresentar como verdade aquilo que, na realidade, diz respeito à fé. Aliás, ele recusava que a ciência, com seus métodos e seus objetivos, pudesse nos oferecer uma concepção de mundo; tampouco a psicanálise, na medida em que sua abordagem do real e seu método excluem qualquer extrapolação possível em direção a uma concepção de mundo, geral e integradora.

O ideal de uma concepção de mundo é bastante atual, como podemos constatar com facilidade observando as duas formas de que ela se reveste: de um lado, a busca, que se tornou bastante comum, de uma relação com a verdade

\footnotetext{
${ }^{7}$ FREUD. "ÜbereineWeltanschauung” (A questão de uma Weltanschauung), in Nouvelles conférences sur la psychanalyse, sétima conferência, 1932a/1971.
} 
que não deixa de revelar um manifesto caráter religioso; mas, também, através dessa forma de religião "laica” representada pela crença popular hoje dominante segundo a qual a ciência — ou a ideia que dela se faz — teria respostas prontas ou ao menos possíveis para todas as questões que podemos encontrar em nossa existência. Contudo, é patente, por outro lado, que a ciência, da forma como ela procede e não segundo os ideais que suscita, não promete nada de semelhante, e não se aventura senão de maneira bastante prudente, até mesmo reticente, no terreno do sentido. Porém, é este mesmo terreno que investe de preferência o ideal de uma concepção de mundo.

Esse ideal está decerto sendo pouco a pouco desmentido na atualidade, pois o que mundo não pode, justamente, integrar é aquilo que é da ordem do objeto recalcado. Este objeto retorna sob formas muito diversificadas do que produzimos: os objetos de consumo e de troca, segundo toda a variedade de suas modalidades de produção. Mas é cada vez mais flagrante que a produção desses objetos não pode ser assimilada ou integrada sem grandes dificuldades àquilo a que estamos acostumados a representar para nós mesmos como nosso "mundo". Se gostaríamos de ignorar que somos comandados por um objeto que não controlamos, uma vez que, como aponta a psicanálise, ele é de início recalcado, esse objeto pode, no entanto, retornar a nós de maneira imprevista e às vezes catastrófica. Um recente acontecimento dessa natureza se produziu há dois anos no Japão, quando do acidente ocorrido na usina nuclear de Fukushima-Daiichi (THIBIERGE, 2015). Este último teve motivos para atrair a atenção, mas poderíamos citar muitos outros. De fato, não controlamos mais grande coisa desses meios para nos tomarmos "como mestres e possuidores da natureza inteira", seguindo o ideal clássico de mestria enunciado por Descartes (1637/1983, p. 168) em seu Discurso do método. A psicanálise, na medida em que se propõe partir de um acontecimento bem diferente, que é o objeto (e não o nosso eu), o qual se encontra em lugar de comando, pode oferecer a vantagem de nos conduzir a uma outra, sem dúvida mais modesta, abordagem do real. Mas isso supõe que se possa aceitar ao menos um pouco ser outro, e não apenas, ou antes de mais nada, uma identidade.

\section{Conclusão}

Ser outro... como compreender isso? Evoquemos, para terminar, duas modalidades e dois encontros possíveis da alteridade, tal como a psicanálise pôde esclarecer e sublinhar a importância.

Uma mulher representa para uma sociedade e para um sujeito, sem dúvida, não apenas, mas por excelência, esta alteridade concebida como o que não pode se definir no fechamento de uma identidade. Freud (1932b/1971) o pressentira 
já em seu célebre artigo de 1932 sobre a feminilidade e Lacan (1972-73/1975) o articulou com precisão mais tarde: o que uma mulher representa não se deixa definir na ordem do conceito ${ }^{8}$. Isto porque, uma mulher está em afinidade com a dimensão do Outro e do desejo. Para ambos os sexos, da mesma forma, o encontro com o desejo é decisivo do seguinte ponto de vista: quando, na adolescência, um rapaz ou uma moça encontram um semelhante suscitando e representando o desejo sexual, fica bem claro que é preciso fazer uma escolha. Ou vamos tentar ir para o lado do desejo, ou então vamos, ao contrário, permanecer ou retroceder do lado do eu. E se formos do lado deste último, será então difícil e, por vezes, impossível, aceder ao desejo.

Notemos, por outro lado, como o funcionamento da letra permite temperar a relação contemporânea com a identidade. Assim que lemos e, de forma notável, quando uma criança aprende a ler, somos obrigados a fabricar e a tecer sentidos, e sentidos possíveis, a partir de alguma coisa que não se apresenta como já tendo um sentido, ou já com uma identidade. É possível constatá-lo também quando redigimos uma carta, seja esta carta escrita à mão ou à máquina: se escrevemos uma carta a um outro que conta muito para nós, ou seja, uma verdadeira carta, somos com frequência surpreendidos ao constatar que, chegados ao fim, estamos em um lugar diferente daquele que pensávamos ir. A carta não é a mesma que imaginamos logo que começamos a escrever. Dito de outra forma, fazemos a experiência, de fato, de uma alteridade fundamental, alteridade que desmente com regularidade esta paixão que podemos sentir ou reivindicar, paixão de ter uma identidade.

Esta atenção colocada no desejo, e mais ainda no encontro com o desejo sexual, independentemente de qual seja ele, ou esta atenção dada à letra e à leitura, são maneiras de nos deixar um pouco menos atormentados e imperiosos em relação à questão da identidade, e ao mesmo tempo um pouco mais dispostos, talvez, com respeito ao que se apresenta como outro. Essa é uma possível orientação prospectiva para a pesquisa, bem como para a política contemporânea, por aliviar um pouco a incidência e o peso, hoje, do sintoma identitário.

Recebido em 1/3/2015. Aprovado em: 23/3/2015.

\footnotetext{
${ }^{8}$ Conforme articulado por Lacan, uma mulher se constitui por referência a uma lógica não-toda fálica. Um dos efeitos dessa posição é que as questões relativas ao feminino não se esgotam ao nível do sentido. Lembramos, contudo, que tais questões encontram no ensino de Lacan uma articulação extremamente rica e complexa cujo desenvolvimento excederia os limites deste artigo. A esse respeito, cf. p. ex. Lacan (1972-73/1975).
} 


\section{REFERÊNCIASS}

DESCARTES, R. (1637/1983) Discours de la méthode, in Euvres et lettres, Paris: Gallimard.

FREUD, S. (1984) Essais de psychanalyse. Paris: Payot.

(1923) «Le Moi et le ça », p.332- 387.

(1925/2011) Inhibition, symptom et angoisse, Paris: PUF.

(1971) Nouvelles conférences sur la psychanalyse. Paris: Gallimard.

(1932a) “Septième conférence”, p.208-241.

(1932b) “Cinquième conférence”, p.147-178.

KIERKEGAARD, S. (1844/1990) Miettes philosophiques, le concept de l'angoisse, traité du désespoir. Paris: Gallimard.

LACAN, J. (1972-73/1975) Encore, Paris: Seuil.

(1962-63/2004) L'Angoisse, Paris: Seuil.

(1966) "Le stade du miroir comme formateur de la fonction du Je” in: Écrits. Paris: Seuil.

MASSAT, A. (2013) "Le succès de l'imposture", in Collection le Midi de la Psychanlyse, Paris: Odile Jacob.

THIBIERGE, S. (2007) Clinique de l'identité. Paris: PUF.

(2015) Fukushima, la vie après, ArtPress, n.423, Paris: ArtPress, p.72-73.

Stéphane Thibierge

thibierge.stephane@gmail.com

Fabiana Campos Baptista

fabianabap@ig.com.br

Natália Vidal

nvidal.psicanalise@gmail.com 